\title{
Diseño de productos y ofertas turísticas competitivas para el desarrollo territorial. Ruta de la Virgen de la Caridad.
}

\begin{abstract}
Product design and competitive tourism offers for territorial development. Route of the Virgin of Charity.
\end{abstract}

Lic. Elizabeth del Carmen Pérez Ricardo., ${ }^{1}$ Lic. Noel Fernández Cueria., ${ }^{2}$ \& MSc. Justa Medina Labrada. ${ }^{3}$

\section{Resumen.}

En el Oriente Cubano están presentes un conjunto de importantes atractivos culturales, entre los cuales se destacan singulares sitios religiosos relacionados con el lugar de aparición de la imagen de la Virgen de la Caridad, la iglesia donde se veneró por primera vez y El Santuario del Cobre, donde se encuentra actualmente este símbolo. Por otra parte, las visitas de su santidad Juan Pablo II, Benedicto XVI y Francisco a Cuba han resaltado con su presencia el valor de instalaciones, que en algunos casos se usan en la operación turística, pero no desde la óptica de ofertas tematizadas con carácter religioso. Por ello se consideró conveniente diseñar ofertas de excursiones ajustadas a los intereses de diferentes mercados así como productos específicos, que no se explotan en la actualidad y que ayudarán al máximo aprovechamiento de los atractivos religiosos y en consecuencia favorecerán el desarrollo turístico competitivo y sostenible de este territorio. Para ello se utilizó la Metodología para la mejora o diseño de productos turísticos y su comercialización propuesta por Funcia Morán et al. (2009), obteniéndose como principal resultado el diseño de diversas ofertas religiosas y del producto turístico Cayo la Virgen enclavado en el municipio de Mayarí, lugar por donde se produjo el hallazgo de la Virgen de la Caridad y que favorecen la competitividad de estos destinos. Las organizaciones públicas correspondientes de las provincias de Holguín y Santiago de Cuba, así como el Gobierno del municipio de Mayarí adoptan acciones para la puesta en valor turístico de las ofertas y el producto diseñado.

\footnotetext{
${ }^{1}$ Universidad de Holguín. Cuba. elizabeth.ricardo@uho.edu.cu

${ }^{2}$ Hotel Brisas Guardalavaca. Cuba.noelfc93@ nauta.cu

${ }^{3}$ Universidad de Holguín. Cuba.jmedina@uho.edu.cu
} 
Palabras claves: atractivos religiosos, diseño de productos y ofertas, desarrollo turístico.

\begin{abstract}
.
In the Eastern Cuba are present a set of important cultural attractions, among which stand out singular religious sites related to the place of appearance of the Virgin of Charity, the church where it was venerated for the first time and The Copper Sanctuary, where this symbol is currently. On the other hand, the visits of his holiness John Paul II, Benedict XVI and Francisco to Cuba have highlighted with their presence the value of facilities, which in some cases are used in the tourist operation, but not from the perspective of offers thematized with character religious. For this reason it was considered convenient to design excursion offers tailored to the interests of different markets as well as specific products, which are not currently exploited and which will help to maximize the use of religious attractions and consequently favor the competitive and sustainable tourism development of this territory. For this, the Methodology for the improvement or design of tourist products and its commercialization proposed by Funcia Morán et al. (2009), obtaining as a main result the design of various religious offers and tourist product Cayo la Virgen located in the municipality of Mayarí, place where the discovery of the Virgin of Charity took place and which favor the competitiveness of these destinations. The corresponding public organizations of the provinces of Holguín and Santiago de Cuba, as well as the Government of the municipality of Mayarí, adopt actions for the promotion of the tourist offer and the designed product.
\end{abstract}

Keywords: religious attractions, product design and offers, tourism development.

\title{
Introducción
}

La industria turística crece sostenidamente con el transcurso del tiempo y teniendo en cuenta los beneficios que genera surgen, aceleradamente, destinos con ofertas y productos sustitutos, provocando así la búsqueda de nuevas alternativas y oportunidades ante el convulso escenario mundial. En función de esto se requiere incorporar productos diferenciadores capaces de satisfacer las necesidades cambiantes de la demanda.

Serra (2003) ha remarcado que "la diferenciación consiste en determinar las características que distinguen la oferta comercial y contribuye a que sea percibida como distinta por los demás". Por otra parte Kotler (2006) señala que "la forma más evidente de diferenciación y, por lo general, la más conveniente para los consumidores es la que se basa en las características del producto o servicio". Por ello si se dispone de productos con atractivos típicos y singulares, sin dudas ello contribuirá a diferenciar la oferta de la cual forme parte.

La actividad turística en Cuba ha desarrollado extensas zonas geográficas, sobre todo las ubicadas en las zonas costeras teniendo en cuenta la preferencia de los clientes por la modalidad de Sol y Playa en los destinos del Caribe. No obstante, en los últimos años se está asistiendo a un cambio en las tendencias de la demanda turística, con lo cual la oferta debe adaptarse a esta nueva situación y posicionarse en zonas hasta ahora alejadas de los polos turísticos. En favor de esto ha sido actualizada la política económica y social del Partido en su VII Congreso, donde se aprobaron una serie de lineamientos, entre ellos el 
208, que establece entre las directrices para el sector turístico "Incrementar la competitividad de Cuba en los mercados turísticos, diversificando las ofertas...".

Holguín se destaca dentro de los destinos cubanos por poseer gran variedad de atributos diferenciadores, sin embargo, un número significativo de ellos no son explotados por el turismo. Entre estos atractivos de gran potencial y poco comercializados en el destino Holguín se destaca la ruta cultural "El camino de la Virgen", en la cual la Oficina del Conservador de la Ciudad de Santiago de Cuba propuso los seis puntos del recorrido que, según el imaginario popular, realizó la Virgen de la Caridad desde su hallazgo en las aguas de la Bahía de Nipe hasta su final ubicación en el poblado del Cobre, los otros cuatro puntos de los territorios de Holguín y Santiago de Cuba donde la Patrona de Cuba fue adorada son: Cayo del Rey, Miranda, Palmarito de Cauto y Hatillo. Esta ruta fue declarada Monumento Nacional en el año 2013 por su relevancia para el pueblo cubano. De estos lugares solo se encuentran aptos para la explotación turística la iglesia católica de Barajagua, vinculada a la existencia de la primera ermita donde se adoró este símbolo y donde yace hoy una escultura de la Virgen en cobre y el Santuario de la Virgen de la Caridad del Cobre, donde permanece la imagen mariana y cuya edificación destaca por su imponente arquitectura ecléctica y el espectacular paisaje donde se encuentra enclavada. Dada la importancia del primer punto del recorrido y su significación histórica, Cayo la Virgen, sitio donde aparece la imagen y al mismo tiempo insertado en una de las mayores bahías de bolsa en el mundo: Bahía de Nipe, se requiere diseñar un producto específico que posea las condiciones adecuadas para la puesta en valor.

En estos momentos no existe ninguna oferta que combine estos atractivos, al no disponerse de una propuesta concreta de diseño que enlace los diferentes productos. Con estos antecedentes se consideró oportuno realizar la presente investigación, que tiene como objetivo general: diseñar ofertas y productos que aprovechen los atractivos relacionados con la Ruta Cultural de la Virgen de la Caridad, la visita del Papa Francisco al Oriente Cubano y que incluyan atractivos históricos y culturales que por su importancia y posición geográfica complementen las mismas, lo que favorecerá la diferenciación y diversificación de la cartera de excursiones del destino turístico Holguín y también de Santiago de Cuba, así como el desarrollo turístico sostenible de estos territorios.

\section{Desarrollo}

El producto es la primera de las $4 \mathrm{P}$ del marketing, es lo que se crea para satisfacer necesidades cambiantes de los clientes. Su desarrollo evita el declive de los destinos turísticos, articula componentes dispersos del conglomerado turístico y a su vez logra desarrollar la actividad turística en determinado espacio (González Ferrer 2011). Algunas razones para renovar y crear nuevos productos son: atacar o igualar a la competencia, dar una respuesta a nuevas necesidades planteadas por los clientes, aprovechar una oportunidad de mercado, ocupar capacidad ociosa, entre otras (González Sainz, 2012).

Existen diversas metodologías para el diseño de productos como son: Martín Fernández (2003),Machado Hernández (2008), Barbosa (2009),Funcia Morán (2009), Koelig Romero (2010), González Sainz (2012) y Cardet Fernández y Palao Fuentes (2012).

Mediante un análisis comparativo de las metodologías referidas anteriormente, se decide utilizar Funcia Morán (2009) para el diseño del producto turístico, por ser la aprobada por 
el Ministerio del Turismo para el diseño de productos turísticos en Cuba y por poseer los pasos fundamentales expuestos en el resto de las metodologías de forma sencilla y asequible permitiendo desarrollar el diseño de productos adecuadamente.

\section{METODOLOGÍA PARA LA MEJORA O DISEÑO DE PRODUCTOS TURÍSTICOS Y SU COMERCIALIZACIÓN.}

Esta metodología abarca seis etapas, y a las que se incorporaron algunas adaptaciones necesarias en concordancia con la investigación, como la inclusión de la etapa 7: Test de concepto del producto, que permita evaluar si existe correspondencia entre los beneficios que aporta y los que busca el cliente. Asimismo, en la etapa 3 se añade el paso: Localización espacial y temporal con el fin de ubicar el nuevo producto geográficamente y en el tiempo que será ofrecido a los clientes, ambas inclusiones, fueron propuestas por González-Sainz (2012). La etapa de Control no será desarrollada en la investigación teniendo en cuenta el alcance de la misma.

Etapa 1. Determinar oportunidades.

Objetivo: identificar o determinar problemas en la gestión del proceso, sentando esta etapa la base para la obtención de productos pertinentes y competitivos.

Paso 1. Demanda del mercado

Este aspecto está orientado a determinar, la cantidad posible de personas por mercadossegmentos actuales y perspectivos con interés en un producto determinado, con los recursos financieros necesarios para adquirirlo y con disposición de ofrecerlo para obtenerlo.

Paso 2. Oferta de productos

Otro de los aspectos a tener en cuenta en el diagnóstico de la situación actual, es la oferta de productos existentes en el destino, empresa y/o instalación turística donde se gestiona el proceso, así como por parte de los competidores (vendedores) para lo cual es importante el análisis de la cartera de productos de los distribuidores.

Paso 3. Competidores

Son los vendedores actuales y perspectivos que ofertan productos similares en los mercados-segmentos emisores, a los que está orientada la gestión de mejora o diseño de productos turísticos que desarrolla un destino, empresa y/o instalación turística.

Paso 4. Oportunidades

La determinación de las demandas de los mercados-segmentos actuales y perspectivos, el análisis de la oferta de los productos existentes por parte del destino, empresa y/o instalación turística donde se gestiona el proceso y el análisis de la oferta de los competidores, permiten precisar las oportunidades que constituyen los ¿Por qué? en dicho proceso.

Etapa 2. Estructurar el producto, el ¿Qué ofrecer? y el ¿Para qué? en la mejora o diseño de productos turísticos. 
Objetivo: Identificar qué ofrecer en el producto, para satisfacer las demandas de los mercados-segmentos actuales y perspectivos.

Paso 5. Potencialidades

La relación que se pone de manifiesto Oportunidades-Potencialidades, constituye parte del diagnóstico de la situación actual, que sirve de punto de partida para la mejora o diseño de productos turísticos y su comercialización.

Paso 6. Objetivos

Teniendo en cuenta la relación Oportunidades-Potencialidades por tipo de producto y demandas de mercados-segmentos, se establece el objetivo específico para la mejora o diseño de productos.

Paso 7. Ideas de productos

La generación de ideas debe estar orientada a proyectar una imagen que resulte atractiva para la demanda-segmento a la cual está dirigida, siendo necesario tener en cuenta los atributos diferenciadores en relación a la competencia.

Paso 8. Nombre del producto

Una correcta formulación del nombre del producto, constituye la base para proyectar una imagen que resulte atractiva para la demanda-segmento a la cual está dirigida, siendo necesario hacer énfasis en los atributos diferenciadores que se ofertan en relación a la competencia. Aspecto este que propicia el logro del posicionamiento en el mercado.

Paso 9. Atractivo y actividades

En el análisis de las potencialidades existentes en el inventario de los recursos turísticos (naturales, históricos, culturales-patrimoniales, eventos, etc.) y la conversión en atractivos se deben tener en cuenta cualidades como:

$\checkmark$ Accesibilidad: Posibilidad de acceso para verlo

$\checkmark$ Autenticidad: Atractivos que no han sido creados por el hombre.

$\checkmark$ Singularidad: Carácter diferenciador, novedad en la atracción de turistas.

$\checkmark$ Posibilidad de realización de Actividades Complementarias: Posibilidad de oferta de actividades compatibles con la atracción o atracciones principales que motivaron el viaje.

$\checkmark$ Calidad: Expresada a través de una buena respuesta a la relación OportunidadesPotencialidades.

Las actividades a realizar deben estar estrechamente relacionadas con el o los atractivos que integran el producto. Para la planificación de actividades hay que tener en cuenta, el segmento de mercado al cual está orientado, el tipo de recurso turístico que sustenta el o los atractivos, así como el nivel de participación de los clientes en cada actividad, entre otras cuestiones.

Paso 10. Mix de servicio

Las selecciones de los servicios constituyen una parte o componente de un producto turístico y sus características están estrechamente relacionadas con: la demanda-segmento 
a la cual va estar orientado el producto, a el tipo de producto en cuestión de que se trate, el atractivo o atractivos que lo integran, las actividades a realizar y los beneficios que se esperan obtener.

Paso 11. Equipamiento e infraestructuras

Los equipamientos e infraestructuras son los medios específicos para satisfacer las necesidades, intereses y deseos de los clientes. Los mismos permiten viabilizar y materializar las ofertas relacionadas fundamentalmente con ¿Qué ver? y ¿Qué Hacer? La selección del equipamiento depende, del tipo de producto así como del tipo de cliente.

Etapa 3. Proceso de prestación

Objetivo: Organizar desde inicio a fin del proceso de prestación, donde hay que prever en el tiempo todos los aspectos necesarios para garantizar la calidad y satisfacción del cliente.

Paso 12. Localización espacial y temporal

Se define la ubicación del nuevo producto geográficamente y el tiempo durante el que será ofrecido a los clientes.

\section{Paso 13. Accesos}

Definir el tipo de transporte (aéreo, terrestre y naval) necesario para acceder al producto y las características del mismo como: capacidad, confort, seguridad, requisitos técnicos, etc.

Paso 14. Transporte

Precisar en fecha y hora todos los servicios de transporte que requiere el producto en el destino, con sus características (marca, capacidad, confort, seguridad, requisitos técnicos, etc.) en correspondencia con la cantidad de clientes, características de los mismos y requisitos para poder recibir los beneficios que ofrece el producto.

Paso 15. Alojamiento

Es necesario precisar fecha y hora de entrada y salida, así como las características del tipo de alojamiento, confort, servicios incluidos y ubicación geográfica en correspondencia con los mercados-segmentos al cual está orientado el producto y de lo previsto en ¿Qué ofrecer?

Paso 16. Restauración

Organizar este servicio en el proceso de prestación mediante la definición de la fecha y hora, así como las características del tipo de restaurante, cafetería y bar previsto en cada momento, comida (buffet, a la carta), especialidad, ubicación geográfica, etc.

Etapa 4. Precio y análisis medioambiental

Objetivo: Prever los costos, gastos, ingresos y la posibilidad de compensar la inversión, con el propósito de lograr rentabilidad con precio de venta competitivo.

Paso 17. Cotizaciones 
Este aspecto está orientado a la elaboración de la ficha de costo del producto. En la ficha de costo debe tener en cuenta, la influencia del número de clientes (turistas), para determinar los costos fijos y los costos variables. A partir del cálculo de los costos y gastos, realizar el cálculo del punto de equilibrio para diferentes variantes de acuerdo al número de clientes que pueden acceder al producto (alto, medio y bajo) y los mercadossegmentos al cual está orientado.

Paso 18. Establecer precio

Derivado del análisis de los resultados obtenidos en el aspecto anterior, podemos establecer el precio por mercados-segmentos para las tres variantes (alto, medio y bajo), teniendo en cuenta además el precio de los productos similares de los competidores del destino.

Paso 19. Viabilidad medioambiental

En el análisis medio ambiental debe tenerse en cuenta, la factibilidad económica, social y geo-ecológica. Un aspecto a considerar en este sentido es el cálculo de la capacidad de carga, la viabilidad técnica, etc.

\section{Etapa 5. Distribución-comunicación}

Objetivo: Lograr que el producto mejorado o nuevo este a la disposición de todos los posibles clientes que lo quieran utilizar.

Paso 20.

- Agencias de viajes (AAVV)

Son los operadores de receptivos dentro del destino y de incentivos fuera del mismo, que su gestión está estrechamente relacionada con uno o más tour operadores.

- Tour operadores (TTOO)

Luego de tener un producto mejorado o nuevo que sea viable desde el punto de vista medio ambiental y contar con Agencias de Viajes interesadas en prestar el servicio de receptivo, se deben realizar acciones para entregarlo a los tour operadores de los mercados-segmentos a lo cual está orientado. Debiéndose tener en cuenta las normas o requisitos de las carteras de los tour operadores.

- Internet

A través de Internet, debemos brindar la posibilidad de que se pueda revisar información e imágenes de los productos mejorados o nuevos, con opciones en las bases de datos que permitan de una forma rápida encontrar las posibles informaciones que buscan los clientes.

- Posicionamiento

Para el logro del éxito en la comercialización del producto mejorado o nuevo, no basta solamente con contar con Agencias de Viajes interesadas en prestar el servicio de receptivo, de que los Tour Operadores tengan el producto y que se encuentre el mismo en Internet. Sino también tener una buena visibilidad y espacio en el catálogo de un tour 
operador en relación a otros productos similares, de forma tal que brinde un carácter diferenciador ante los posibles clientes.

- Acciones promocionales

$\checkmark$ Entre las acciones promocionales se encuentran:

$\checkmark$ Ferias Turísticas

$\checkmark$ Viajes de Familiarización

$\checkmark$ Encuentro de Empresarios

- Mix comunicacional

El mix comunicacional tiene como propósito influir en los posibles clientesmediante la información que se brinda, para que compren el producto mejorado o nuevo. Para el logro del objetivo, entre los aspectos a considerar están los siguientes:

$\checkmark$ Publicidad

$\checkmark$ Promoción de Venta

$\checkmark$ Relaciones Públicas (RRPP)

$\checkmark$ Venta Personal o Fuerzas de Ventas

$\checkmark$ Otras: Entre ellas se encuentran el Sistema de Información al Visitante, que es atendido fundamentalmente en Cuba por los Centros de Información Turística (INFOTUR) y las Oficinas Promoción Tur. Exterior. La marca, la cual propicia identificar y diferenciar los productos que son similares en relación con el tipo de producto o su utilización

Etapa 6. Test de producto

Objetivo: Identificar la correspondencia que existe entre los beneficios del producto y los que el cliente espera recibir, así como la aceptación de los especialistas.

Paso 21. Test de producto

Para la evaluación de la pertinencia del producto se decide realizar un test de producto con el objetivo de identificar la correspondencia que existe entre los beneficios del producto y los que el cliente espera recibir, así como la aceptación de los especialistas.

\section{Resultados}

Resultados de la aplicación de la metodología para la mejora o diseño de productos turísticos y su comercialización.

Por su relevancia en la historia y tradición del pueblo cubano y debido a que el turismo religioso es una modalidad que está en auge porque fideliza los visitantes que van a este tipo de destinos turísticos y congrega anualmente aproximadamente 220 - 250 millones de fieles, fue diseñada la oferta "Por la ruta cultural el camino de la Virgen", con el fin de cumplir además con la tendencia actual de integrar modalidades o visitar multidestinos donde el cliente encuentre la combinación de atractivos naturales, culturales, religiosos $\mathrm{u}$ otros; así como aprovechar a los mercados que visitan el destino holguinero con interés cultural y religioso como Canadá, Alemania, Italia, Polonia, Estados Unidos y el mercado nacional y atraer a otros mercados potenciales como Argentina, Venezuela y México que visitan la isla, así como Brasil dada su relevancia entre los países de mayor población 
católica del mundo; contribuyendo también a diversificar y diferenciar la oferta del destino Holguín.

El diseño de esta oferta abarca tres de los puntos originales por donde transitó y fue adorada la Virgen de la Caridad: Cayo de la Virgen, lugar donde aparece la imagen y al mismo tiempo insertado en una de las mayores bahías de bolsa en el mundo: Bahía de Nipe; la iglesia católica de Barajagua, vinculada a la existencia de la primera ermita donde se adoró este símbolo y donde yace hoy una escultura de la Virgen y por último el Santuario del Cobre, lugar donde permanece la imagen de la Virgen y cada día cientos de personas muestran su devoción a esta en misas y peregrinajes, edificación que destaca por su imponente arquitectura ecléctica y el espectacular paisaje donde se encuentra enclavada.

A la oferta se le realizaron adaptaciones según las características y preferencias de los mercados meta, obteniéndose tres variantes de la misma. Sin embargo, a pesar de la novedad de la oferta, esta no ha sido puesta en explotación por las agencias de viajes del territorio a pesar de que ha sido muy bien valorada, manifestando que Cayo de la Virgen requiere conformar un producto con los atributos necesarios para una adecuada explotación turística. De ahí la necesidad de diseñar además el producto turístico "Cayo la Virgen".

Diseño de la oferta turística "Por la ruta de la Virgen"

En el destino turístico holguinero el flujo de visitantes es garantizado con la entrada de 49 vuelos semanales directos al aeropuerto internacional Frank País (Pichs Rodríguez 2016), principalmente procedentes de Canadá, país que emitió un total de 154266 visitantes el pasado 2016, Inglaterra con 39 049, Alemania 20 614, además del mercado nacional que reportó un total de 122462 visitantes y otros como Italia, Polonia y EE. UU (MINTUR 2016).

Entre los mercados tradicionales del destino varios poseen gran advocación católica: Canadá (el $41 \%$ de su población es católica), Alemania (34\%), Italia (80\%), Polonia (88\%), Estados Unidos (24\%) y el mercado nacional; otros países que constituyen mercados potenciales del Holguín también poseen gran advocación católica como son: Brasil (64\%), Venezuela (96\%), Argentina (92\%), México (83\%) y Colombia (90\%). (www.saberespractico.com 2014). Brasil es el primer país con más católicos del mundo, seguido de México y luego Estados Unidos.

El producto se diseña con el objetivo de atraer a grupos de clientes de los mercados que visitan el destino holguinero con interés cultural y religioso, de ahí que se escojan para la determinación del público objetivo los mercados reales: Canadá, Alemania, Italia, Polonia, Estados Unidos y el mercado nacional. Entre los mercados potenciales se seleccionan: Argentina, Venezuela y México que visitan la isla, así como Brasil dada su relevancia entre los países de mayor población católica del mundo.

El destino turístico Holguín combina de forma singular el sol y la playa, la naturaleza, la historia, la arqueología, la cultura y las tradiciones locales. Sin embargo, un análisis realizado al catálogo de opcionales de las agencias de viajes del territorio holguinero demostró que muchas de estas reservas para el desarrollo del turismo no son comercializadas en su totalidad. Solo una parte de ellas se incluyen en la cartera de 
productos de las agencias de viajes del destino predominando los naturales que se incorporan a la náutica como se muestra en el gráfico siguiente:

Figura 1. Tipología de las excursiones del destino. 2017

\section{Total de excursiones del destino}

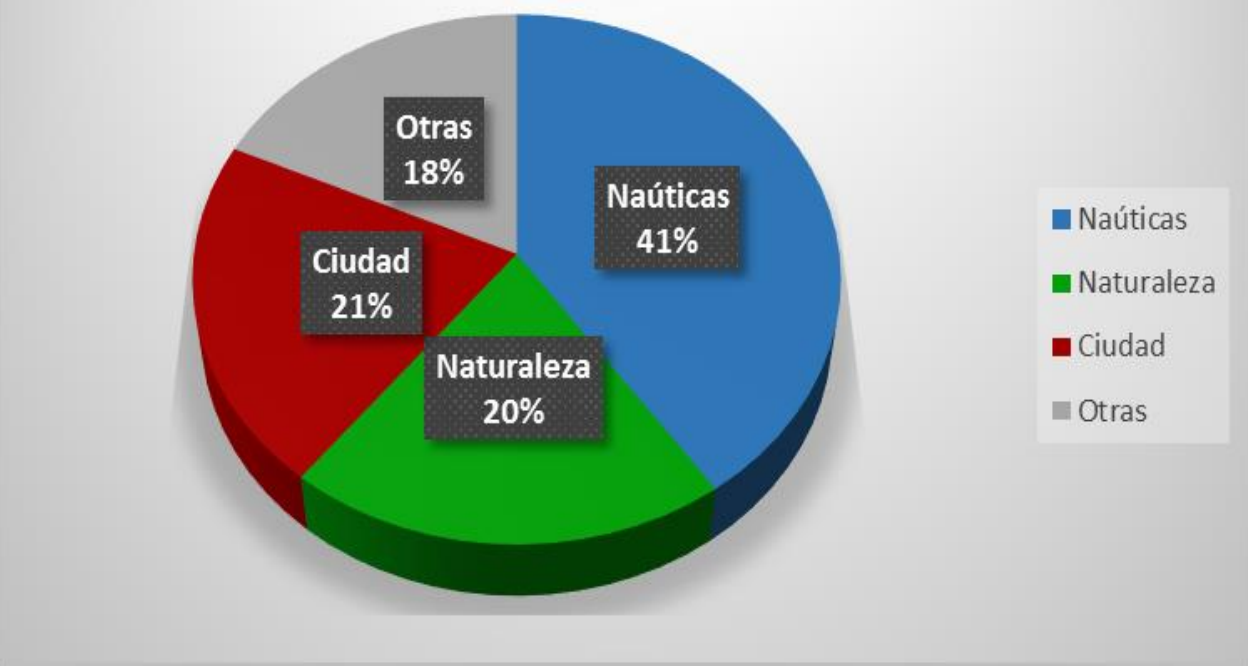

Como se evidencia en el gráfico anterior la mayoría de las excursiones del destino se concentran en la náutica y en cifra similar las de ciudad y naturaleza. No obstante, los atractivos que se incluyen en cada una son reiterados en las demás, lo que demuestra la poca diferenciación de estas opcionales. Los atractivos del destino que más se incluyen en las excursiones son: Bahía de Naranjo, fincas campesinas, Boca de Samá y los parques de Holguín. Otros de gran interés para los mercados meta son excluidos de las excursiones. Entre estos se encuentra: la ruta cultural "El camino de la Virgen" declarada Monumento Nacional.

Muchos son los atractivos que destacan a lo largo del camino, en primer lugar la imagen de la Virgen de la Caridad símbolo religioso de toda una nación; la Bahía de Nipe, lugar donde aparece la imagen y al mismo tiempo es una de las mayores bahías en el mundo; la iglesia de Barajagua vinculada a la escultura de la Virgen en Cobre; el Santuario de la Virgen de la Caridad del Cobre, lugar donde se sitúa la imagen de la Virgen y cada día cientos de personas muestran su devoción a esta en misas y peregrinajes, la Basílica, además, destaca por su imponente arquitectura ecléctica y el espectacular paisaje asociado a ella. Actualmente estos atractivos no son comercializados integradamente por ninguna agencia de viajes por no existir una propuesta concreta de diseño. No obstante existe una demanda potencial que se evidencia en las visitas al Santuario Basílica de Nuestra Señora, experiencia vivida por miles de personas motivados por diversas circunstancias, así como el peregrinaje que realizan personas de diferentes provincias y países para la entrega de exvotos u ofrendas.

Por ello fueron diseñadas un conjunto de ofertas turísticas tematizadas que integran estos atractivos religiosos y otros culturales de gran relevancia ubicados en las provincias de Holguín y Santiago de Cuba, entre ellos lugares visitados por el Papa Juan Pablo II, Benedicto XVI y Francisco . Estas ofertas consideran las características y preferencias de 
distintos mercados y segmentos a la hora de determinar la duración de las excursiones, precios y atractivos a visitar.

La oferta que abarca un mayor número de atractivos es "Por la ruta de la Virgen", la cual inicia el recorrido en Cayo de la Virgen, donde el guía explicará la leyenda de la aparición de la Virgen en la bahía y serán señalados además los puntos relacionados con el hallazgo, que se pueden observar desde la costa, como el obelisco que se erige con la imagen de la Virgen de la Caridad, las ruinas de la antigua ermita y la tarja que identifica al sitio como Monumento Nacional declarado el 7 de septiembre de 2012.

Luego se visita la iglesia de Barajagua declarada Monumento Nacional, donde un bohío en el mismo centro del hato de Barajagua indicaría el espacio en que germina la veneración a la Virgen de la Caridad y donde yace una escultura de la Virgen en bronce. El siguiente punto es la ciudad de Santiago, donde se trasladan los clientes por sitios importantes de la historia y cultura santiaguera como la Catedral, el Cementerio Santa Ifigenia, el Castillo San Pedro de la Roca. El check in se efectuará en el Hotel Casagranda ubicado en el centro de la ciudad y a la mañana siguiente visitarán el poblado del Cobre.

Al llegar al Santuario del Cobre podrán participar de forma opcional en la misa y realizar la entrega de exvotos $u$ ofrendas a la Virgen. Una vez en el interior del santuario apreciarán la arquitectura del lugar, conocerán acerca de la visita del Papa Juan Pablo a la isla y la coronación de La Virgen como la Patrona de Cuba, así como el Papa Benedicto XVI y el ramo de rosas de oro obsequiadas a Nuestra Señora de la Caridad, podrán apreciar además el cáliz de plata entregado por el Papa Francisco en su visita a la Isla y el sillón ocupado por él. Contemplarán el entorno donde el agreste perfil de la sierra y la evidencia de tradiciones complementan la existencia de un paisaje cultural, donde se destaca la presencia de las primeras minas de cobre a cielo abierto explotadas en América y el lago de azul intenso como resultado de la explotación de las antiguas minas de cobre y la escultura del cimarrón, símbolo de importantes protestas esclavas.

De regreso a la ciudad de Holguín se visita al Conjunto Monumentario Birán, que incluye la casa natal de Fidel y Raúl Castro Ruz y otras instalaciones como la escuelita, la valla de gallo, el bar, el hotel, la carnicería, panadería, etc. que formaban parte de las propiedades de la vida de la familia Castro Ruz. Además se hará referencia al Camino Real por donde fue transportada la Virgen hacia el hato de Barajagua. Una vez en la ciudad se accede a la Loma de la Cruz, desde donde el Papa Francisco bendijo la misma y donde se les hace entrega a los clientes de un souvenir elaborado por un artesana holguinera.

Una vez que el cliente arribado al destino y compre la opcional podrá acceder a cada uno de los puntos del recorrido por vía terrestre, para ello utilizaría un ómnibus perteneciente a TRANSTUR o Gaviota Tours en dependencia de la agencia comercializadora; la capacidad del ómnibus será de 24 pax aunque esto puede variar según las ventas. Además se requiere el servicio de un ZIL 132 capaz de transitar el camino hacia bahía de Nipe cuya capacidad es de 22 pax. La restauración es otro de los servicios que se ofertan, los snacks se ofertarán en el ómnibus y el almuerzo se efectuará en un restaurante o paladar de la ciudad de Santiago, mientras que el hospedaje, cena y desayuno se efectuarán en el Hotel Casa Granda. 
Después de realizar los cálculos económicos pertinentes se define como precio de la opcional 149 cuc, requiriéndose un mínimo de 10 pax. Para motivar que los clientes potenciales compren el nuevo producto es necesario divulgar información que despierte interés por el mismo, construyendo de esta manera una imagen propia, favorable y sostenida en el tiempo difícil de imitar. A continuación se proponen un conjunto de actividades:

- Promocionar el producto en revistas seculares y de tendencias católicas

- Incluir el producto en guías turísticas, afiches, folletos y catálogo del destino

- Realizar viajes de familiarización donde se invite a líderes de opinión y TTOO

- Ubicar plegables que comuniquen con exactitud los atractivos del producto en los mostradores de ventas en los hoteles.

Teniendo en cuenta la necesidad de enriquecer Cayo de la Virgen, primer punto del recorrido, donde existen un conjunto de atractivos que no están disponibles para la explotación debido al deterioro actual y considerando además la propuesta del importante artista plástico Cosme Proenza para construir un oratorio en el lugar, se decidió estructurar este nuevo producto, que complementará los atributos que existen actualmente.

Diseño del producto turístico "Cayo la Virgen"

Se analizaron las oportunidades existentes para el diseño del nuevo producto turístico, a través de la valoración de los factores internos (fortalezas y debilidades) y externos (oportunidades y amenazas).

$>$ Debilidades

1. Lejanía del cayo delos principales polos turísticos del territorio

2. Mal estado del vial de acceso terrestre

3. Carencia de infraestructura turística

$>$ Fortalezas

1. Es un atractivo auténtico del país pues refleja el hecho del hallazgo de la Virgen de la Caridad

2. El sitio está declarado como Monumento Nacional

3. El atractivo se inserta en las aguas de la bahía de Nipe, una de las mayores bahías de bolsa del mundo y la mayor de la Isla

4. En el lugar se pueden integrar modalidades, pues se combinan valores culturales, religiosos, naturales y náuticos

5. En el cayo está concebido el diseño de un monumento realizado por el importante artista plástico Cosme Proenza

6. La ubicación favorece su inclusión dentro de las ofertas náuticas del destino que son las más vendidas por las agencias de viajes

$>$ Oportunidades

1. En el año 2016 se manifestó un crecimiento en la llegada de turistas a la isla del $14.6 \%$ con respecto al año anterior

2. Actualización de la política económica y social del Partido en su VII Congreso, donde se aprobaron una serie de lineamientos, entre ellos el 208, que establece entre las directrices para el sector turístico "Incrementar la competitividad de Cuba en los mercados turísticos, diversificando las ofertas..." 
3. Se prevé un incremento de 19000 habitaciones para el turismo en la península del Ramón de Antilla

4. Atractivos de gran interés no son comercializados por las agencias de viajes del destino Holguín

5. En todo el orbe se registra una movilización cercana a los 330 millones de personas que viajan por motivos religiosos, con una derrama económica estimada en 18 mil millones de dólares estadounidenses (World Religious Travel Association, 2015)

6. Entre los mercados tradicionales del destino Holguín con mayor advocación católica se encuentran los países Canadá (41\%), Alemania (34\%), Italia (80\%), Polonia (88\%) y Estados Unidos (24\%)

$>$ Amenazas

1. Poco reconocimiento del nuevo producto en el destino

Luego del análisis realizado se puede determinar que las condiciones del entorno son favorables para el diseño del producto turístico considerando las fortalezas y oportunidades y proponiendo soluciones alternativas para las debilidades y amenazas.

Se diseña un producto turístico cultural-religioso basado en la leyenda del hallazgo de la Virgen de la Caridad en las aguas de Bahía de Nipe. La historia de la aparición de la imagen mariana permite determinar como el primer lugar de su culto una barbacoa en playa Morales, sitio que se destaca porque en conmemoración a esto se erigió un obelisco frecuentado por peregrinos y visitantes. Además, posee la categoría de Monumento Nacional, dada su relevancia para el país. En la actualidad se proyecta construir un oratorio diseñado por el importante artista plástico holguinero Cosme Proenza, asimismo se propone el establecimiento de un espacio de venta de alimentos ligeros y bebidas, un área de artesanías y preparar las vías de acceso terrestre y marítima a este punto.

Durante el reconocimiento del lugar fueron identificados los recursos y atractivos turísticos presentes en el entorno, para lo cual se tuvo en cuenta cualidades como accesibilidad, autenticidad y posibilidad de realizar actividades complementarias. A continuación, se realiza una descripción de los principales atractivos:

\section{La Virgen de la Caridad}

La Virgen de la Caridad del Cobre es la patrona de los cubanos. Algunos la conocen simplemente como "Cachita". Desde tiempos inmemorables en cada hogar de Cuba se puede ver un cuadro o una reliquia con la imagen de la Virgencita. Representa la Virgen María Santísima con un Niño Jesús en sus brazos y una cruz. La imagen original, la misma que fue encontrada en los mares al norte de Oriente hace más de 400 años, se encuentra actualmente y se venera en la Basílica Santuario Nacional de Nuestra Señora de la Caridad del Cobre en Santiago de Cuba. (Oficina del Conservador de la ciudad 2011).

Leyenda del hallazgo de la Virgen

Según fuentes históricas, la imagen de la Virgen fue encontrada entre los años 1604 y 1613 por tres obreros (dos descendientes de indios, Juan y Rodrigo de Hoyos y un niño negro, Juan Moreno) que habían ido en busca de sal a las salinas existentes en cayo Francés, en el centro de la bahía de Nipe, cerca de la desembocadura del Río Mayarí. Ellos vieron que algo flotaba sobre la espuma del agua. Al principio creyeron que era un 
pájaro y luego una niña. Finalmente, al acercarse, comprendieron que era la imagen de una virgen sobre una tablilla pequeña con unas letras inscritas que decían: "Yo soy la Virgen de la Caridad". Se asombraron de que sus vestiduras no estuvieran mojadas a pesar de navegar sobre una frágil tablilla y la noche de tormenta anterior y tomaron el hecho como un milagro y una buena señal religiosa (Oficina del Conservador de la ciudad 2011). Estas personas que posteriormente fueron conocidos como los Tres Juanes, llevaron la imagen hasta donde vivían, en el Hato de Barajagua a orillas del Rio Cauto. Allí fue situada en un rústico altar dentro de un bohío, donde comenzó su veneración. Más tarde la imagen fue trasladada al antiguo poblado Real de Minas, en Santiago de Cuba (Oficina del Conservador de la ciudad 2011).

Oratorio

En la actualidad se proyecta construir un oratorio en Cayo de la Virgen, diseñado por el importante artista plástico Cosme Proenza. El mismo sería un lugar dedicado a actividades sagradas en la que los visitantes puedan participar voluntariamente.

Obelisco

En el sitio también se erige un obelisco de madera con la imagen mariana en la parte superior del mismo. Este fue levantado allí en el año 2009 como símbolo de la adoración a la Patrona de Cuba. Actualmente permanecen en él ofrendas entregadas por los que visitan el lugar.

Atractivos secundarios:

Cayo Obispo

A unos dos kilómetros del Cayo de la Virgen, en el interior de la bahía, se localiza Cayo Obispo, denominado en el siglo XVII Cayo Francés o Vigía, en el cual, luego de una tormenta pernoctaron tres noches los dos indios y el negro esclavo protagonistas de la leyenda del hallazgo de la Virgen. Allí se han encontrado evidencias arqueológicas y conserva una tupida vegetación. Todo el paisaje fue transformado por el ciclón Flora en 1963. Cuentan que la costa era recta y cuando la marea bajaba se podía ir hasta el Cayo Obispo caminando.

Artesanías

Un área de artesanías peculiares de carácter religioso se contemplaría como parte del diseño del nuevo producto. Variedades de estatuillas, imágenes, libros, llaveros y otros recuerdos podrían adquirir los visitantes como parte inolvidable de la experiencia alcanzada.

Actividades

Las principales actividades a realizar durante la visita al producto serían:

- Conocer la leyenda del hallazgo de la Virgen de la Caridad

- Participar en las actividades sagradas programadas en el oratorio

- Apreciar el valor paisajístico de Cayo de la Virgen que debe su nombre a la aparición de esta divinidad en esas aguas, también el obelisco allí levantado, símbolo de la adoración a la Patrona de Cuba, así como las ofrendas que son 
depositadas en este, las ruinas de la antigua ermita y la placa de declaración de Monumento Nacional

- Tomar fotografías de la bahía más grande de la isla rodeada por las lomas del grupo de Maniabón y la Sierra de Nipe

- Comprar artesanías peculiares en el lugar

Para la explotación del producto es necesario organizar los equipos que permiten materializar los servicios anteriormente referidos. La transportación vía terrestre se puede realizar en ómnibus turísticos según la agencia que comercialice el producto, ya sea TRANSTUR o TRANSGAVIOTA. Estos medios dispondrán de gran seguridad y confort. Asimismo, se pueden emplear camiones ZIL de Gaviota jeeps turísticos, los cuales son apropiados según las cualidades técnicas de la vía actualmente. El acceso por vía marítima se efectuará mediante catamaranes, contratados previamente a la Marlin o la Marina de Gaviota, el horario dependerá del itinerario de la excursión y la cantidad será de acuerdo al número de pax movidos.

El equipamiento que se propuso utilizar en el lugar se aprecia en el Anexo 7:

En el oratorio: un estante para depositar ofrendas.

En la edificación: dos expositores de bebidas refrescantes,

En el área de artesanías: varias mesas

Infraestructura técnica y de apoyo: solución eléctrica a través de paneles solares, abasto de agua a partir de suministro alternativo, solución de residuales que sea económica y compatible con el medio ambiente.

Para realizar los cálculos económicos previstos se consideró que en los análisis con el Gobierno de Mayarí y el Obispado de Holguín, que serán los encargados de financiar las obras, se planteó la necesidad de acometer las mismas por etapas, cuyo alcance fueron definidas por estas entidades. A partir de ello se solicitó al ingeniero Blas Ramírez Fernández, de amplia experiencia en el cálculo del presupuesto de inversiones, que estimara el costo de los objetos de obra de la 1ra etapa. A partir de lo antes expuesto se puede concluir que la inversión necesaria para ejecutar el proyecto del Oratorio en Cayo de la Virgen y el resto de las acciones de reparación en el cayo es de un valor de 42504.95CUP.

Se propone por la investigadora que las agencias de viaje que comercialicen el producto paguen un cuc por cada pax al administrador del sitio que es la Empresa de Flora y Fauna de Mayarí, considerando que es necesario introducir y posicionar el producto. De esta manera se puede recuperar la primera etapa de la inversión en 15 meses, considerando que el lugar reciba dos veces por semana grupos de 15 pax cada uno.

Algunas de las acciones comunicativas del producto en Internet son:

- Crear una cuenta en Facebook con el objetivo de atraer seguidores y que los clientes compartan su experiencia al disfrutar del producto, además se podrán exponer fotos, descripciones y otras relacionadas con él

- Colocar el producto en los mapas de Google para que esté visible en la web el producto y a su vez facilite la accesibilidad a este 
- Incorporar el producto en la aplicación cubana de Geocuba "Andariego", con el objetivo de que sea reconocido nacionalmente y se identifique su ubicación

- Situar el producto en Trip Advisor, descripciones y fotos para que los clientes puedan subir sus comentarios al respecto y así se genere un intercambio de opiniones sobre el mismo

- Crear un blog para el producto en Blogger o WordPress el cual puede funcionar como sitio propio y se pueden publicar fotos, información y comentarios

- Contactar con administradores de sitios web de carácter religioso para proveer información del producto, como son: turismoreligioso.com (Una propuesta turística de interés religioso, cultural y gastronómico, para visitar los caminos de la $\mathrm{Fe}$, parroquias, iglesias, monumentos y sitios sacros.)

- Comunicar a través de la página del centro de Información Turística (INFOTUR)

Para la evaluación de la pertinencia del producto se decide realizar un test de producto a clientes y uno a especialistas, con el objetivo de identificar la correspondencia que existe entre los beneficios del producto y los que el cliente espera recibir, así como la aceptación de los especialistas. A continuación, se muestran los principales resultados:

Al consultar a los 7 especialistas seleccionados, cuyos datos se relacionan en el Anexo 12, se comprobó que el $100 \%$ de ellos consideran que el producto "Cayo la Virgen" satisface los intereses y preferencias de los mercados meta estudiados. Además, manifestaron en su totalidad que recomendarían el producto diseñado a clientes. El $70 \%$ de los mismos refirieron sugerencias interesantes para mejorar el producto, entre ellas: Incorporar en el cayo medios de información (carteles) con la historia del hallazgo de la Virgen para que el cliente que visite el producto individualmente pueda conocer la historia, incorporar el mercado nacional como público objetivo del producto dado que un alto porcentaje de la población es católica y la identificación que posee con la Virgen de la Caridad, Patrona de Cuba, y su ascendente posicionamiento en el destino como uno de los principales mercados, así como incluir dentro de las actividades a realizar en el cayo el baño en la playa. Algunas de estas sugerencias fueron incorporadas al diseño, otras no resultaron convenientes según los requerimientos del producto.

Por otra parte, fueron encuestados 17 clientes de diferentes nacionalidades y edades, de ellos el $41 \%$ practica alguna religión y el $70 \%$ conoce sobre la Virgen de la Caridad. Asimismo, el 59\% de los clientes manifestaron que sí comprarían el producto, el 29\% refieren que probablemente y solo un $12 \%$ expresó que no lo compraría. A partir de la información obtenida se puede afirmar que el producto "Cayo la Virgen" resulta atractivo para los clientes que actualmente visitan el destino. Asimismo, los especialistas aseveran la pertinencia del mismo. 


\section{Conclusiones}

$>$ Se analizaron diferentes procedimientos empleados para el diseño de productos turísticos, escogiéndose para desarrollar el diseño del producto "Cayo la Virgen" el de Funcia Morán et al. (2009) al que se le realizaron algunas adaptaciones, en correspondencia con las necesidades de la investigación.

$>$ Fueron diseñadas un conjunto de ofertas turísticas tematizadas que integran atractivos religiosos y culturales de las provincias de Holguín y Santiago de Cuba y que consideran las características y preferencias de distintos mercados y segmentos, las que contribuyen a diferenciar la oferta de excursiones y hacerla más competitiva.

$>$ Se diseñó el producto turístico específico "Cayo la Virgen", punto inicial y relevante de las ofertas, el cual requería mejoras para una comercialización más efectiva.

\section{Referencias Bibliográficas}

Cardet Fernández E. y Palao Fuentes, R. (2012).Procedimiento para el diseño y desarrollo de productos.

Funcia Morán, C. et al. (2009). Metodología para la mejora o diseño de productos turísticos y su comercialización (MEPROTUR).

González Ferrer, J. (2011). Material para el módulo de Desarrollo de Productos de la Maestría en Gestión Turística. 3ra edición. Holguín.

González Sainz, Y. (2012). Propuesta de diseño del producto turístico Centro Recreativo Cultural El Molino Rojo de Gibara. Tesis en opción al título de Licenciado en Turismo. Universidad de Holguín.

Koelig Romero, M. (2010). Diseño de un producto turístico de carácter patrimonial.

Kotler, P., Bowen, J. y Makens, J. (2004). Marketing para Turismo. Madrid: Prentice Hall.

Machado Hernández C. (2008). Procedimiento para el diseño de un producto turístico integrado en Cuba, Universidad de Las Villas.

Martín Fernández, R. (2003). Fundamentos del Turismo. Centro de Estudios Turísticos. Universidad de La Habana.

MINTUR. (2016). Informe Comercial del MINTUR. Holguín.

Partido Comunista de Cuba. (2016). Actualización de los lineamientos de la Política Económica y Social del Partido y la Revolución para el período 2016-2021. 
Pichs Rodríguez, L. Vuelos semanales a Holguín. Recuperado de: aldia.cu (Publicado: 23/02/2016).

Serra, A. (2003). Marketing turístico. Madrid: Ediciones Pirámide.

Sitio "El Cobre". (2011). Expediente Declaratoria como Monumento Nacional. Santiago de Cuba. Oficina del Conservador de la ciudad. 


\section{Para citar el artículo indexado.}

Pérez E., Fernández N. \& Medina J. (2017). Diseño de productos y ofertas turísticas competitivas para el desarrollo territorial. Ruta de la Virgen de la Caridad. Revista electrónica Explorador Digital 1(2), 59-77. Recuperado desde:

http://cienciadigital.org/revistacienciadigital2/index.php/exploradordigital/article/view/322/7 $\underline{34}$

\section{Ciencia \\ Digital \\ Editorial}

El artículo que se publica es de exclusiva responsabilidad de los autores y no necesariamente reflejan el pensamiento de la Revista Explorador Digital.

El articulo queda en propiedad de la revista y, por tanto, su publicación parcial y/o total en otro medio tiene que ser autorizado por el director o editor de la Revista Explorador Digital.
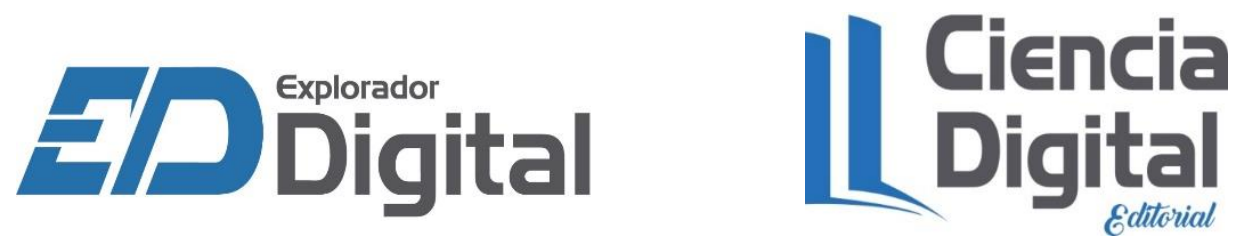